\title{
A low-cost solid-liquid separation process for enzymatically hydrolyzed corn stover slurries
}

\author{
David A. Sievers ${ }^{\mathrm{a}, *}$, James J. Lischeske ${ }^{\mathrm{a}}$, Mary J. Biddy ${ }^{\mathrm{a}}$, Jonathan J. \\ Stickel $^{\mathrm{a}}$ \\ ${ }^{a}$ National Bioenergy Center, National Renewable Energy Laboratory, 15013 Denver \\ West Parkway, Golden, CO, 80401, USA
}

\begin{abstract}
Solid-liquid separation of intermediate process slurries is required in some process configurations for the conversion of lignocellulosic biomass to transportation fuels. Thermochemically pretreated and enzymatically hydrolyzed corn stover slurries have proven difficult to filter due to formation of very low permeability cakes that are rich in lignin. Treatment of two different slurries with polyelectrolyte flocculant was demonstrated to increase mean particle size and filterability. Filtration flux was greatly improved, and thus scaled filter unit capacity was increased approximately 40-fold compared with unflocculated slurry. Although additional costs were accrued using polyelectrolyte, techno-economic analysis revealed that the increase in filter capacity significantly reduced overall production costs. Fuel production cost at $95 \%$ sugar recovery was reduced by $\$ 1.35$ US per gallon gasoline equivalent for dilute-acid pretreated and enzymatically hy-
\end{abstract}

\footnotetext{
*Corresponding author. Tel.: 303-384-7748.

Email address: David.Sievers@nrel.gov (David A. Sievers)
} 
drolyzed slurries and $\$ 3.40$ for slurries produced using an additional alkaline de-acetylation preprocessing step that is even more difficult to natively filter.

Keywords:

flocculation, solid-liquid separation, filtration, biofuels, enzymatic hydrolysis

\section{Introduction}

Biofuels from non-food sources have the potential to reduce greenhousegas emissions and increase energy independence by offsetting the consumption of fossil fuels (Slade et al., 2014). Researchers have made significant progress in recent years towards making biofuels production an economically viable process (Humbird et al., 2011; Tao et al., 2012). A typical biofuels conversion process begins with a thermo-chemical pretreatment step followed by enzymatic hydrolysis to convert the remaining carbohydrates to sugars. These sugars are then upgraded to fuels like ethanol or butanol through fermentation (Zhang et al., 1995; Sedlak and Ho, 2004), or to other, usually deoxygenated, hydrocarbons by means of fermentation or catalytic upgrading (Roman-Leshkov et al., 2007; Besson et al., 2014; Degirmenci and Hensen, 2014).

It is potentially useful to include a solid-liquid separations step after enzymatic hydrolysis to provide a solids-free sugar stream for downstream processing. Solids have been shown to interfere with the fermentation of 
sugars to ethanol (Zhang et al., 2009), and we expect these solids would also present problems in a hydrocarbon process. Insoluble solids likely would plug the flow paths of catalyst beds during aqueous-phase reforming and these solids may also present oxygen transfer limitations during aerobic fermentations by impacting the agitation/sparging efficiency or altering the available bubble surface area through coalescence with solids. If the product is not excreted by the microorganism into the broth and requires cell lysis or extraction, the presence of extra solids could also increase the cost of product recovery. Additionally, the lignin-rich residual solids stream has potential chemical value elsewhere in a biofuels refinery if not burned for combined heat and power (Davis et al., 2013; Ragauskas et al., 2014). Although solid-liquid separation of enzymatic hydrolyzate presents possible advantages or may be required, it is difficult to perform. The residual insoluble solids have been reduced in fibrous cellulose and hemi-cellulose content while fine lignin particles remain and dominate. In our experience, this slurry stream forms rather impermeable filter cakes, and also performs poorly in buoyancy-driven separation processes like centrifugation and sedimentation.

Only a few separation studies have been published for these materials. Kinnarinen et al. (2013) examined the use of cellulosic filter-aids with pressure filtration and observed modest improvements. Another study evaluated the use of polyelectrolyte flocculants with pretreated and enzymatically hydrolyzed pine and obtained $12 \times$ improved centrifugation separation 
performance and $40 \times$ flux improvement in a vacuum filtration assembly (Burke et al., 2011). Finally, Leberknight and Menkhaus (2013) performed a chemical analysis of filter-plugging using dilute acid-pretreated and enzymatically hydrolyzed ponderosa pine wood and determined that lignin was the primary chemical agent responsible for plugging. A few membrane treatments were evaluated for their ability to reduce plugging by lignin particles. To the authors' knowledge, no solid-liquid separation studies exist in the public domain that use pretreated and enzymatically hydrolyzed corn stover; neither are there any published studies that performed a thorough economic analysis of the costs associated with including filtration as a unit operation in the context of an integrated bio-refinery.

Bulk filtration with and without the use of flocculating polymers was examined in the current study for the removal of solids from sugar streams after enzymatic hydrolysis. Dead-end filtration using a vacuum filter was chosen over other alternatives such as tangential flow filtration or centrifugation, as this method provides greatest concentration of solids and recovery of liquor. An experimental evaluation of a possible polishing filtration step was also performed. We examined the sensitivity of our separations process to a different pre-processing step prior to pretreatment, specifically the addition of a caustic de-acetylation step, as in Chen et al. (2012). Finally, a techno-economic analysis was performed based on the process configurations presented, with a post-enzymatic hydrolysis separations step included. The results are analyzed on the basis of change in fuel production 
cost.

\section{Materials and Methods}

\subsection{Corn Stover Hydrolyzate}

Pretreated and enzymatically hydrolyzed corn stover slurries ("hydrolyzate") were prepared from corn stover using two different processing conditions depicted in Figure 1. Under the first condition, referred to as the "standard" case, dry feedstock was soaked in $2.0 \%$ wt $\mathrm{H}_{2} \mathrm{SO}_{4}$ at $7 \%$ total solids concentration by mass. This dilute slurry was de-watered to $50 \%$ total solids in a Vincent, Inc. (Tampa, FL, USA) screw press, then pretreated in a steam-pressurized reactor at $158^{\circ} \mathrm{C}$ for 5 min. The resulting pretreated biomass was diluted to $20 \%$ total solids, $\mathrm{pH}$ neutralized, and hydrolyzed for three days in a paddle blender at $50^{\circ} \mathrm{C}$ using Novozymes CTEC 2 (Franklinton, NC, USA) at $20 \mathrm{mg}$ protein/g glucan, resulting in a slurry with $5.0 \%$ insoluble solids concentration.

Under the second condition, referred to as the "de-acetylated" case, feedstock was subjected to an alkaline preconditioning step using $0.55 \%$ $\mathrm{NaOH}$ at $7 \%$ total solids for $30 \mathrm{~min}$ at $100^{\circ} \mathrm{C}$. This material was rinsed of caustic, soaked in a $0.3 \% \mathrm{H}_{2} \mathrm{SO}_{4}$ solution, de-watered as above, and then pretreated at $160^{\circ} \mathrm{C}$ for 10 minutes. This pretreated biomass was enzymatically hydrolyzed as described above, but at $10 \mathrm{mg}$ protein/g glucan and for five days, resulting in a $6.7 \%$ insoluble solids concentration slurry. These process parameters were chosen as part of a separate study to drive 
enzyme requirements down and reduce acetic acid concentrations. Virgin feedstock and both hydrolyzed materials were tested for insoluble solids composition, and the results are shown in Tables 1 and 2 .

\subsection{Flocculation}

Kemira, Inc. (Atlanta, GA, USA) KemSep C-7107 branched polyamide with $10 \%$ cationic molar charge and 10 MDa molecular weight was used to flocculate the hydrolyzate slurries. The stock solution of polymer was diluted to a $10 \mathrm{~g} / \mathrm{kg}$ working solution. This solution was added to the slurries in laboratory beakers and mixed with a laboratory marine impeller of $50 \mathrm{~mm}$ diameter at $200 \mathrm{rpm}$. At the target dosing used here $(8 \mathrm{~g}$ stock polyelectrolyte / kg insoluble solids for standard case; $10 \mathrm{~g} / \mathrm{kg}$ for de-acetylated case) large globular flocs were formed initially and subsequently broke down to distinct particular flocs with further mixing. Mixing was stopped when the floc size appeared by eye to be about $1 \mathrm{~mm}$ in diameter. A sam-

ple of the flocculated slurry was taken and the floc particle size distribution was determined by computational microscopy image analysis using a Leica DM3000 microscope (Bannockburn, IL, USA) and Clemex Vision PE software (Longueuil, QC, Canada). Flocs had previously been observed to disintegrate after aging for more than twelve hours and analysis was performed the same day as flocculation. Virgin un-flocculated slurry particle size distribution was also measured using a Malvern Mastersizer 2000 (Houston, TX, USA). 


\subsection{Bulk Filtration}

A $100 \mathrm{~cm}^{2}$ Outotec, Inc. (Jessup, MD, USA) Büchner-filter bench-top test unit was used to test filtration of the hydrolyzate slurries. Based on previous experience, a predetermined mass of slurry was applied to the Buchner filter to achieve a target cake thickness. Vacuum was applied and mother liquor collected until no liquid remained above the cake, at which time the vacuum was paused and wash water was added on top of the cake. This is a qualitative determination with important implications: if vacuum was stopped too soon, the cake was not set firmly and could reslurry with the subsequent application of wash water; if too much liquid was withdrawn from the cake, the cake would crack and separate from the vessel walls, allowing channeling of wash water. These issues were more pronounced with the flocculated slurries than with the raw slurries. After wash water was added, the vacuum was re-applied. Wash filtrate was collected as distinct fractions, with vacuum interrupted between fractions to swap collection tubes. Wash water remained on top of the filter cake and ceased to flow when vacuum was broken between fractional collections. At the end of each washing experiment, all wash water was consumed and subsequently air was pulled thorugh the filter cake to purge as much liquor as possible from the cake. Filtrate quantity and HPLC glucose concentration of each fraction, determined per Sluiter et al. (2008), were used to quantify how much glucose remained in the filter cake at each wash volume interval. 
Two filter cloths were used for this experiment, which are also identical to the scaled versions used on vacuum belt filters: Outotec, Inc. MARO S30 (air permeability of $2.4 \mathrm{~m}^{3} / \mathrm{m}^{2} \cdot \min$ at $2 \mathrm{kPa}$ ) for non-flocculated hydrolyzate, and MARO S60 (air permeability of $12 \mathrm{~m}^{3} / \mathrm{m}^{2} \cdot$ min at $2 \mathrm{kPa}$ ) for flocculated hydrolyzate. Preliminary experiments with non-flocculated material demonstrated significantly poorer filtration rate on the more permeable cloths, possibly due to fouling of the larger pores with fine particles, while there was no such problem with flocculated hydrolyzates. Vacuum filtration of non-flocculated hydrolyzate was carried out with a vacuum pressure of 0.51 bar, while vacuum filtration of flocculated hydrolyzate was carried out at 0.34 bar. The filter apparatus was disassembled after each run and the filter cloth was peeled from the cake to test for clean separation from the cloth if scaled to an automatic filter unit. Following cake discharge, the filter cloths were rinsed with water (as is normal practice in a scaled belt filter) and then permeability was tested in the filter apparatus using only water to compare filtration rates before and after use with slurry. All cakes separated readily from the filter cloths and water permeability of the filter cloths was not impacted following use and rinsing, indicating these two cloths are suitable for these slurries from a technical standpoint.

Filtration capacity, $C\left(\mathrm{~kg} / \mathrm{m}^{2} \mathrm{~h}\right)$, of scaled filter equipment was readily 
calculated from bench top Buchner test results by

$$
C=\frac{m_{t} w_{s}}{t A}
$$

where $m_{t}(\mathrm{~kg})$ is the total mass of the slurry filtered, $w_{s}$ is the mass fraction of insoluble solids in the slurry, $t(\mathrm{~h})$ is the cumulative filtration time, and $A\left(\mathrm{~m}^{2}\right)$ is the filter area. Cumulative filtration time was calculated as the sum of initial measured filtration time to form a moist cake, total cake washing time as measured for the wash volume of interest, and the time to complete the air purge step following washing.

\subsection{Polishing Filtration}

An Advantec (Dublin, CA, USA) stainless-steel filter housing that holds $25 \mathrm{~mm}$ disk filters was used to test polishing filtration in a dead-end mode. A Millipore (Billerica, MA, USA) NY1102500 nylon filter with a pore-size of $11 \mu \mathrm{m}$ was used to screen the filterability of the mother liquors obtained from bulk filtration. Additionally, the de-acetylated case filtrate liquor was used to evaluate a higher order sterile filtration scenario using a Millipore "Durapore" GVWP02500 membrane with $0.20 \mu \mathrm{m}$ pore size and a Millipore GNWP02500 nylon filter with $0.22 \mu \mathrm{m}$ pore size. A modified version of Darcy's Law was used to calculate specific filtration resistance, $R(1 / \mathrm{m})$, omitting membrane thickness for simplicity.

$$
R=\frac{A \Delta P}{Q \mu}
$$


where $A\left(\mathrm{~m}^{2}\right)$ is the membrane area, $\Delta P(\mathrm{~Pa})$ is the applied filtration pressure, $Q\left(\mathrm{~m}^{3} / \mathrm{s}\right)$ is the measured permeate flowrate, and $\mu(\mathrm{Pa} \cdot \mathrm{s})$ is the filtrate viscosity which was assumed constant and that of water $(0.001 \mathrm{~Pa} \cdot \mathrm{s})$.

\section{Results and Discussion}

\subsection{Flocculation}

Flocculation is a process by which colloidal particles aggregate within a disperse solution through alteration of the solid-liquid interface using electrolytes or surface-active agents, or by adjustment of physical conditions. Flocculation increases effective particle size and is helpful for improving the efficiency of solid-liquid separations (Svarovsky, 2000). Electrolytes act to neutralize the net surface charge of particles, which allows aggregation of solids that are normally kept in suspension by opposing electrostatic forces. Electrically charged polymers (polyelectrolytes) induce flocculation by both charge neutralization and interparticle bridging. Polyelectrolytes with high molecular weights, on the order of several million daltons, are able to accu-

mulate a large mass of solids per molecule. Polyelectrolytes with side-chain branching may offer further flocculation capacity by increasing inter-floc bridging and floc structural integrity.

In evaluating this technology for use in filtration of enzymatic hydrolysis slurries, we needed to balance two competing effects. Larger floc sizes generally filter more easily, potentially enabling higher filter capacities. However, the liquor entrained within the flocs contains our chemical of 
interest; in this case, glucose. Larger flocs will retain more liquor, and in a diffusion-driven washing regime like the static liquid in the flocs, washing effectiveness will scale with the cube of floc diameter. During initial experimentation, an approximate floc size of $1 \mathrm{~mm}$ represented a reasonable balance in size and also was more stable than larger flocs during agitation. Stability is important in a scaled industrial system involving pumps and piping where floc aging (disintegration over time) is undesirable after the target size is reached. Through trial and error, we achieved this floc size by adding the flocculant at the dosage described in section 2.2 , then mixing with a marine impeller until the flocs appeared to be $1 \mathrm{~mm}$ by visual inspection. Particle size distributions of raw and flocculated slurries are shown in Figure 2, which indicates flocculation was highly effective at increasing the particle size of the slurry. The mean particle size for nonflocculated material was $23 \mu \mathrm{m}$, and approximately $1200 \mu \mathrm{m}$ for flocculated material, a difference of nearly two orders of magnitude. These characteristics were similar between the standard and de-acetylated materials.

It may be possible to further optimize the flocculation procedure whereby the same floc size can be achieved with less flocculant dosage (Real et al., 2014). However, we observed that increasing flocculant dose also increased floc structural integrity, i.e. the flocs were less sensitive to shear. We recommend that a systematic optimization of the flocculation chemical and dosing procedure be performed once the upstream unit operations and process slurry characteristics are well-established. 


\subsection{Bulk Filtration}

Two replicates of a single experiment (bulk filtration of flocculated deacetylated case hydrolyzate) are shown in Figure 3, and is representative of the degree of repeatability for these bulk filtration and washing experiments. On the horizontal-axis, sugar recovery is the cumulative amount of filtrate sugars, as a fraction of feed slurry sugars, recovered by filtration and successive cake washing. The left-vertical-axis (solid lines) is filtration capacity (mass solids processed per filter area per unit time), which is a design parameter relating required time and filter area to the desired yield of the filtration process, and is calculated by equation 1 . The right-verticalaxis (dashed lines) indicates the amount of wash water required to achieve the desired sugar recovery per unit mass of filtered solids.

Overall results for the full set of bulk filtration experiments are presented in Figure 4, with filter capacity and the amount of wash water required plotted against the fraction of sugars recovered as in Figure 3. The sugar recovery of a simple filtration step with no washing was $\sim 70 \%$ for both standard non-flocculated cases (Figure 4a), and ranged from 50 to $60 \%$ for flocculated cases (Figure 4b). Washing was more efficient, on a water consumption basis, for non-flocculated materials, with sugar recovery approaching asymptotic recovery using only $5 \mathrm{~L}$ of water per $\mathrm{kg}$ of cake solids, compared to 20 to $25 \mathrm{~L} / \mathrm{kg}$ required for the same sugar recovery in the flocculated case. This can be attributed to liquor retention within flocs, which restricts early recovery and subsequently limits the extrac- 
tion of sugars from the flocs in a diffusion-dominated process. However, flocculation dramatically increased filtration rate and therefore filtration capacity. At filtrate sugar recovery of $95 \%$ just before the asymptotic performance region, both flocculated cases demonstrated a filtration capacity of $\sim 25 \mathrm{~kg} / \mathrm{m}^{2} \mathrm{~h}$, significantly higher than the capacities for the unflocculated slurries of 1.8 and $1.2 \mathrm{~kg} / \mathrm{m}^{2} \mathrm{~h}$ for the standard and the deacetylated cases, respectively. At $70 \%$ recovery, which is representative of a simple no-wash filtration for the non-flocculated case, the flocculated materials demonstrated a filtration capacity of 70 to $100 \mathrm{~kg} /\left(\mathrm{m}^{2} \mathrm{~h}\right.$ ) (while using 2 to $3 \mathrm{~L} / \mathrm{kg}$ wash water), compared to $\sim 2.5 \mathrm{~kg} /\left(\mathrm{m}^{2} \mathrm{~h}\right)$ for both non-flocculated materials with no washing. Together, these constitute an improvement in filter capacity of $15-40 \times$, depending on sugar recovery requirements. Filter capacity is inversely proportional to the required number of filter units and capital expense in a commercial production setting.

The potential impact of residual flocculant on downstream processing was not examined in this work. Evidence from Burke et al. (2011) indicates that any residual flocculant would not impact a typical fermentation process. Also, any impact on a catalytic upgrading step would be specific to the chemistry of the catalyst and is therefore outside the scope of this paper. 


\subsection{Polishing Filtration}

The filtrate liquor from each bulk filtration was filtered again through a NY1102500 nylon membrane, with a nominal pore size of $11 \mu \mathrm{m}$, and results are shown in Figure 5(a). For some applications, such as aqueousphase reforming with catalyst particles of sufficient size, removal of solids larger than $11 \mu \mathrm{m}$ may be sufficient to avoid fouling. None of the liquors resulted in monotonically increasing resistance associated with plugging (Ho and Zydney, 2000), indicating solids larger than $11 \mu \mathrm{m}$ were already removed by earlier bulk filtration of the slurry and that a secondary filtration of this type may be unnecessary for some applications.

However, a more aggressive secondary filtration may be needed in other applications. For example, it may be desirable to sterile-filter bulk filtrate liquor to remove contaminating microorganisms prior to fermentation. Therefore, the liquor resulting from bulk filtration of flocculated de-acetylated case hydrolyzate (along with water as a control) was filtered through two sterile-grade filters (Millipore GNWP02500, a nylon membrane with nominal pore size of $0.22 \mu \mathrm{m}$, and Millipore GVWP02500, a Durapore membrane with nominal pore size of $0.20 \mu \mathrm{m}$ ), and the results are shown in Figure 5(b), along with results from the $11 \mu \mathrm{m}$ nylon filter for comparison. The sterile-grade filters exhibited plugging behavior that indicates the presence of membrane-fouling species, perhaps fine solids, residual flocculant, or microorganisms. If polishing filtration of this order is necessary, additional flocculation and filtration development, including sanitary proce- 
dures, may be required.

\subsection{Economic Analysis}

A preliminary techno-economic analysis was performed utilizing the design report of Davis et al. (2013), which describes the biological aerobic conversion of lignocellulosic sugars to free fatty acids followed by hydroprocessing to a renewable diesel blendstock. Since this is an aerobic conversion process, removal of solids prior to biological conversion is required to improve biological conversion. Continuous vacuum belt filters were used in this model to perform separation after enzymatic hydrolysis where sugarrich liquor was sent to fermentation and residual lignin was used as boiler fuel for the biorefinery.

The experimental results for filter capacity, wash water consumption, and sugar recovery were incorporated into the model for economic evaluation. Utilizing the calculated filter capacity, the required number of parallel filter systems needed for the design flow rate was estimated for a given filter unit area. Each vacuum belt filter unit was assumed to have a useable area of $170 \mathrm{~m}^{2}$ at a capital cost of $\$ 2,461,000$ (2013 US dollars) (Sievers et al., 2014). Flocculant doses were based on experimental data from this study and the cost of the flocculant was based on the Davis et al. (2011) analysis for algal production of fuels (which is roughly $\$ 11$ per $\mathrm{kg}$ in 2011 US dollars).

Figure 6 summarizes the impact of improved sugar recovery using floc- 
culant on the estimated fuel selling price for a given recovery efficiency. Due to the much higher filter capacity when flocculants were used, the required number of filter units was decreased in all cases, often by an order of magnitude. The large reduction in capital cost due to reduction in required filter units more than compensated for the increase in the operation cost due the addition of flocculants. An overall reduction in the minimum fuel selling price of produced hydrocarbon biofuels was observed when flocculant was used versus none, and greater savings were realized when sugar recovery requirement was pushed to higher levels since filtration capacity on the non-flocculated slurry severely diminished. Greater savings were observed when the de-acetylation process was used because the untreated enzymatic hydrolyzate produced in this case is even more difficult to filter than the standard hydrolyzate and thus an even larger economic advantage is offered by flocculation. At 95\% sugar recovery, the largest impacts on the price are reported with cost improvements of $\$ 1.35$ and $\$ 3.40$ per gallon of gasoline equivalent for the standard and de-acetylated cases, respectively. Optimization of the flocculation process for the particular slurry is expected to reduce polyelectrolyte dose and costs, which would further improve upon these numbers.

\section{Conclusions}

Treatment of two different enzymatically hydrolyzed corn stover slurries with polyelectrolyte flocculant was demonstrated to greatly increase mean 
particle size and aid filterability. Filtration capacity was increased up to $40 \times$ when the slurries were flocculated compared with untreated. Although flocculated slurry required more wash water and additional costs were accrued for polyelectrolyte, techno-economic analysis revealed the large increase of filter capacity reduced overall production cost significantly. Fuel minimum selling price was reduced by $\$ 1.35$ for the standard process material and $\$ 3.40$ per gallon gasoline equivalent for the de-acetylated process material at sugar recovery of $95 \%$.

\section{Acknowledgements}

This work was funded by Award EE0005006 (Cellulosic Biomass Sugars to Advantaged Jet Fuel) from the Bioenergy Technologies Office of EERE, US Department of Energy. This work occurred in partnership with Virent, Inc. We thank Kemira, Inc. for supplying flocculants for this study, and also Jessica Olstad (National Renewable Energy Laboratory), who performed laser diffraction particle size measurements.

\section{References}

[1] Besson, M., Gallezot, P., Pinel, C., Feb 2014. Conversion of biomass into chemicals over metal catalysts. Chem. Rev. 114, 1827-1870.

[2] Burke, D. R., Anderson, J., Gilcrease, P. C., Menkhaus, T. J., Jan 2011. Enhanced solid-liquid clarification of lignocellulosic slurries using polyelectrolyte flocculating agents. Biomass Bioenerg. 35, 391-401. 
[3] Chen, X., Tao, L., Shekiro, J., Mohagheghi, A., Decker, S. R., Wang, W., Smith, H., Park, S., Himmel, M. E., Tucker, M., 2012. Improved ethanol yield and reduced minimum ethanol selling price (MESP) by modifying low severity dilute acid pretreatment with deacetylation and mechanical refining: 1) Experimental. Biotechnol. for Biofuels 5, 60.

[4] Davis, R. H., Aden, A., Pienkos, P. T., 2011. Techno-economic analysis of autotrophic microalgae for fuel production. Appl. Energy 88.10, $3524-3531$.

[5] Davis, R. H., Tao, L., Tan, E. C. D., Biddy, M. J., Beckham, G. T., Scarlata, C., Jacobson, J., Cafferty, K., Ross, J., Lukas, J., Knorr, D., Schoen, P., 2013. Process design and economics for the conversion of lignocellulosic biomass to hydrocarbons: Dilute-acid and enzymatic deconstruction of biomass to sugars and biological conversion of sugars to hydrocarbons. Tech. Rep. NREL/TP-5100-60223, National Renewable Energy Laboratory, Golden, CO, USA.

[6] Degirmenci, V., Hensen, E. J. M., Jul 2014. Development of a heterogeneous catalyst for lignocellulosic biomass conversion: Glucose dehydration by metal chlorides in a silica-supported ionic liquid layer. Environ Prog Sustain Energy 33, 657-662.

[7] Ho, C., Zydney, A., 2000. A combined pore blockage and cake filtration model for protein fouling during microfiltration. J. Colloid Interface Sci. 232, 389-399. 
[8] Humbird, D., Davis, R. H., Tao, L., Kinchin, C., Hsu, D., Aden, A., 2011. Process design and economics for the conversion of lignocellulosic biomass to ethanol: Dilute-acid pretreatment and enzymatic hydrolysis of corn stover. Tech. Rep. NREL/TP-5100-47764, National Renewable Energy Laboratory, Golden, CO, USA.

[9] Kinnarinen, T., Golmaei, M., Hakkinen, A., Oct 2013. Use of filter aids to improve the filterability of enzymatically hydrolyzed biomass suspensions. Ind. Eng. Chem. Res. 52, 14955-14964.

[10] Leberknight, J., Menkhaus, T. J., Sep 2013. Membrane separations for solid-liquid clarification within lignocellulosic biorefining processes. Biotechnol. Prog. 29, 1246-1254.

[11] Ragauskas, A. J., Beckham, G. T., Biddy, M. J., Chandra, R., Chen, F., Davis, M. F., Davidson, B. H., Dixon, R. A., Gilna, P., Keller, M., Langan, P., Naskar, A., Saddler, J. N., Tschaplinski, T. J., Tuskan, G. A., Wyman, C. E., 2014. Lignin valorization: Improving lignin processing in the biorefinery. Science 344 (6185), 1246843.

[12] Real, G. E. G. d., Davies, J., Bracewell, D. G., 2014. Scale-down characterization of post-centrifuge flocculation processes for highthroughput process development. Biotechnol. Bioeng. 111, 2486-2498.

[13] Roman-Leshkov, Y., Barrett, C. J., Liu, Z. Y., Dumesic, J. A., Jun 
2007. Production of dimethylfuran for liquid fuels from biomassderived carbohydrates. Nature 447, 982-985.

[14] Sedlak, M., Ho, N. W. Y., Spr 2004. Production of ethanol from cellulosic biomass hydrolysates using genetically engineered saccharomyces yeast capable of cofermenting glucose and xylose. Appl. Biochem. Biotechnol. 113, 403-416.

[15] Sievers, D. A., Tao, L., Schell, D. J., 2014. Performance and technoeconomic assessment of several solid-liquid separation technologies for processing dilute-acid pretreated corn stover. Bioresour. Technol. 167, 291-296.

[16] Slade, R., Bauen, A., Gross, R., 02 2014. Global bioenergy resources. Nature Clim. Change 4, 99-105.

[17] Sluiter, A., Hames, B., Ruiz, R., Scarlata, C. Sluiter, J., Templeton, D., 2008. Determination of sugars, byproducts, and degradation products in liquid fraction process samples. laboratory analytical procedure. Tech. Rep. NREL/TP-510-42623, National Renewable Energy Laboratory, Golden, CO, USA.

[18] Svarovsky, L., 2000. Solid-Liquid Separation, 4th Edition. Butterworth-Heinemann, Oxford.

[19] Tao, L., Schell, D. J., Elander, R. T., Bratis, A., 2012. Biochemical 
platform state of technology report. Tech. rep., National Renewable Energy Laboratory, Golden, CO.

[20] Zhang, J. Y., Shao, X. J., Lynd, L. R., Dec 2009. Simultaneous saccharification and co-fermentation of paper sludge to ethanol by saccharomyces cerevisiae RWB222. Part II: Investigation of discrepancies between predicted and observed performance at high solids concentration. Biotechnol. Bioeng. 104, 932-938.

[21] Zhang, M., Eddy, C., Deanda, K., Finkestein, M., Picataggio, S., Jan 1995. Metabolic engineering of a pentose metabolism pathway in ethanologenic zymomonas-mobilis. Science 267, 240-243. 


\section{List of Figures}

1 Process flow diagram for both Standard and De-Acetylated cases of slurry production. . . . . . . . . . . . . . . . 23

2 Particle size distributions of untreated and flocculated deacetylated hydrolyzate, measured by image analysis and laser diffraction. . . . . . . . . . . . . . . . . . . . . . . 24

3 Filter capacity (solid lines) and water consumption (dashed lines), presented as a function of sugar recovery, for replicated vacuum filtration test of flocculated de-acetylated slurry. 25

$4 \quad$ Filter capacity (solid lines) and water consumption (dashed lines) results for the standard case (red, square markers) and de-acetylated case (blue, circle markers), presented as a function of sugar recovery. Results for standard non-flocculated slurries are presented in (a), and results for flocculated slurries are presented in (b). . . . . . . . . . . . . 26

$5 \quad$ The results of polishing filtration on all bulk filtrates using filters with nominal pore size of $11 \mu \mathrm{m}$ (a), and results from two types of sterile filters $(0.22 \mu \mathrm{m}$ Millipore type GNWP, and $0.20 \mu \mathrm{m}$ Millipore type GVWP) used on the de-acetylated case (b) with water presented as controls in both. DeA = de-acetylated case, $\mathrm{Std}=$ standard case. Increasing resistance over volume indicates plugging. . . . . . . . . . . . 27

6 Techno-economic analysis of an enzymatic hydrolyzate solidliquid separator, demonstrating change in minimum fuel selling price at $10 \%$ internal rate of return (change in production cost) when filter feed stream has been flocculated versus no treatment. . . . . . . . . . . . . . . . . . . . . . 28 


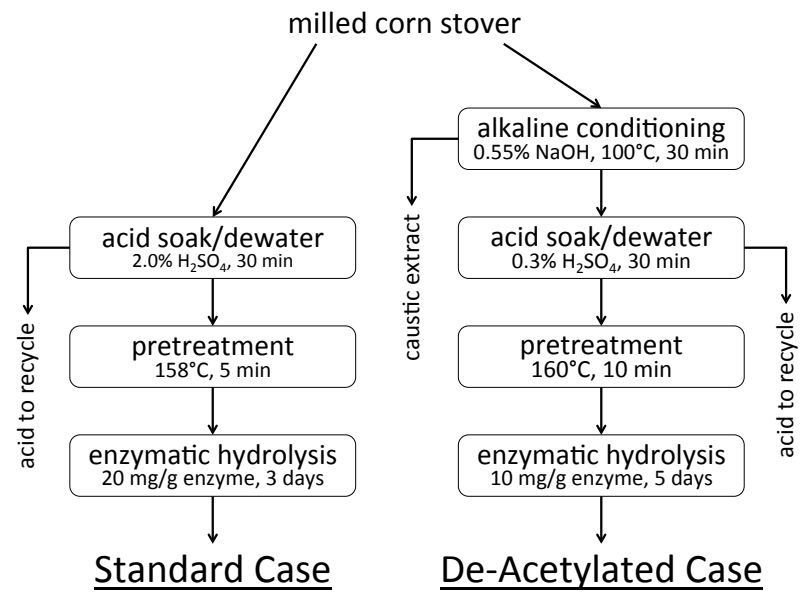

Figure 1: Process flow diagram for both Standard and De-Acetylated cases of slurry production. 


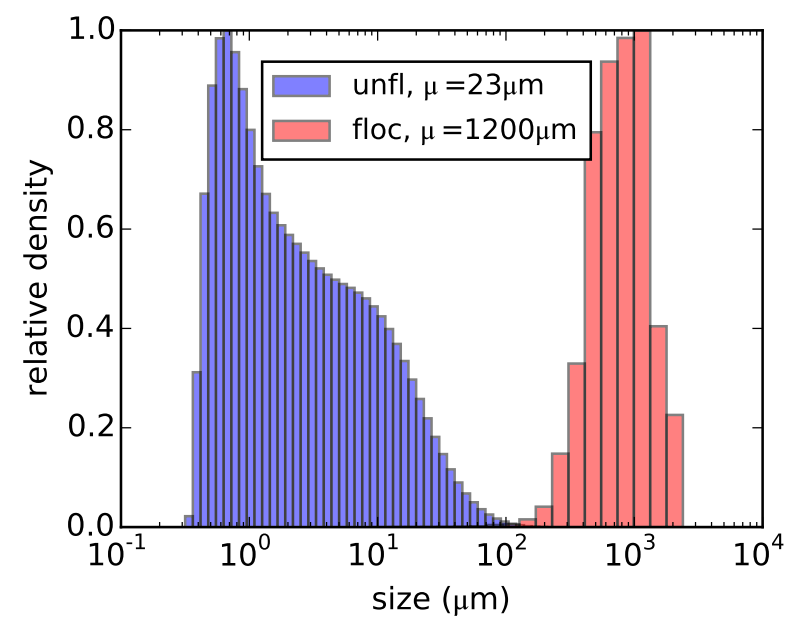

Figure 2: Particle size distributions of untreated and flocculated de-acetylated hydrolyzate, measured by image analysis and laser diffraction. 


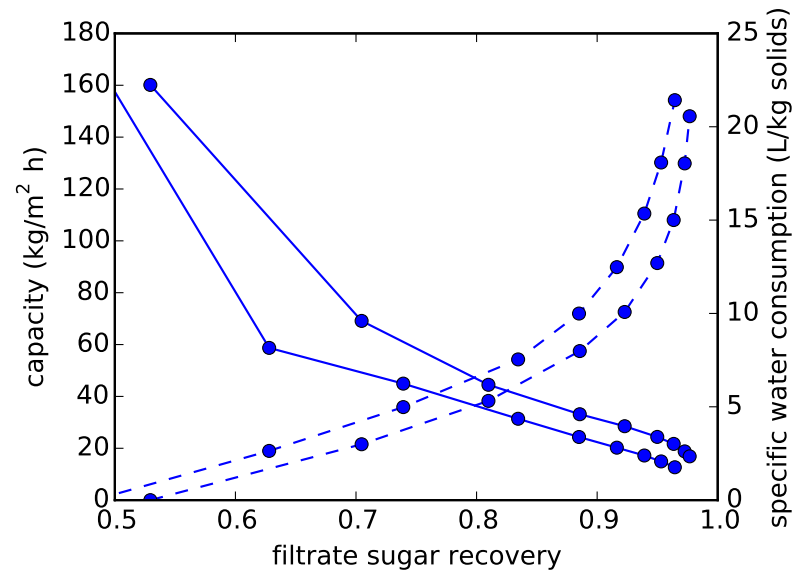

Figure 3: Filter capacity (solid lines) and water consumption (dashed lines), presented as a function of sugar recovery, for replicated vacuum filtration test of flocculated de-acetylated slurry. 


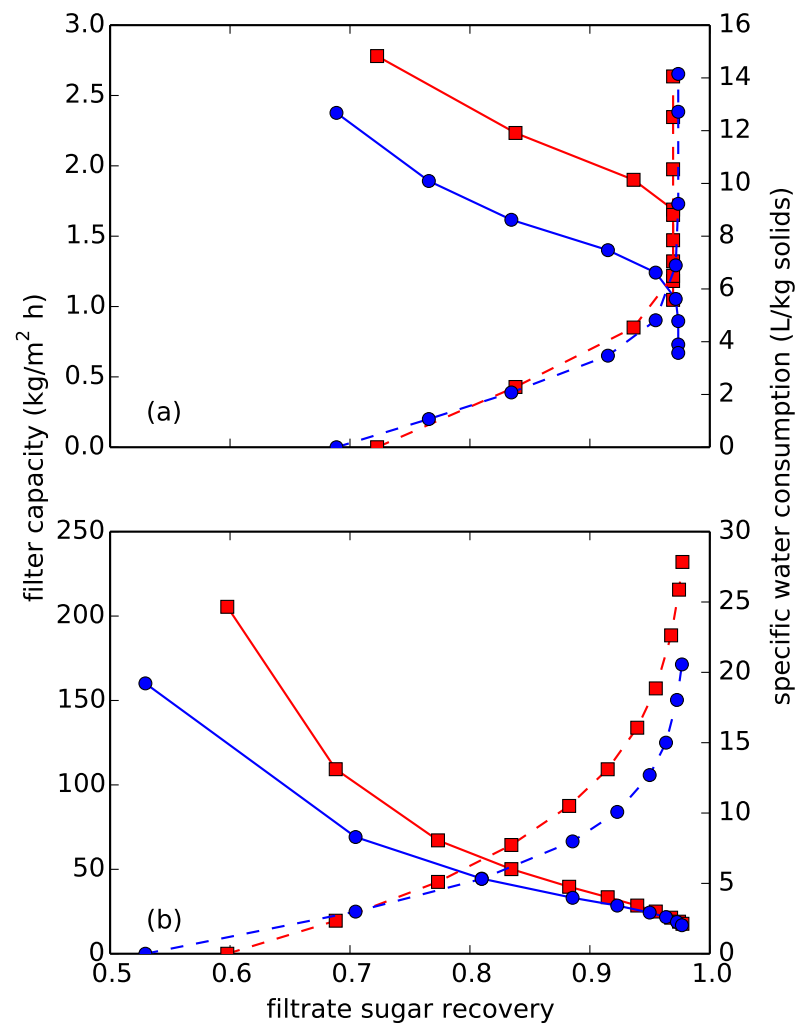

Figure 4: Filter capacity (solid lines) and water consumption (dashed lines) results for the standard case (red, square markers) and de-acetylated case (blue, circle markers), presented as a function of sugar recovery. Results for standard non-flocculated slurries are presented in (a), and results for flocculated slurries are presented in (b). 

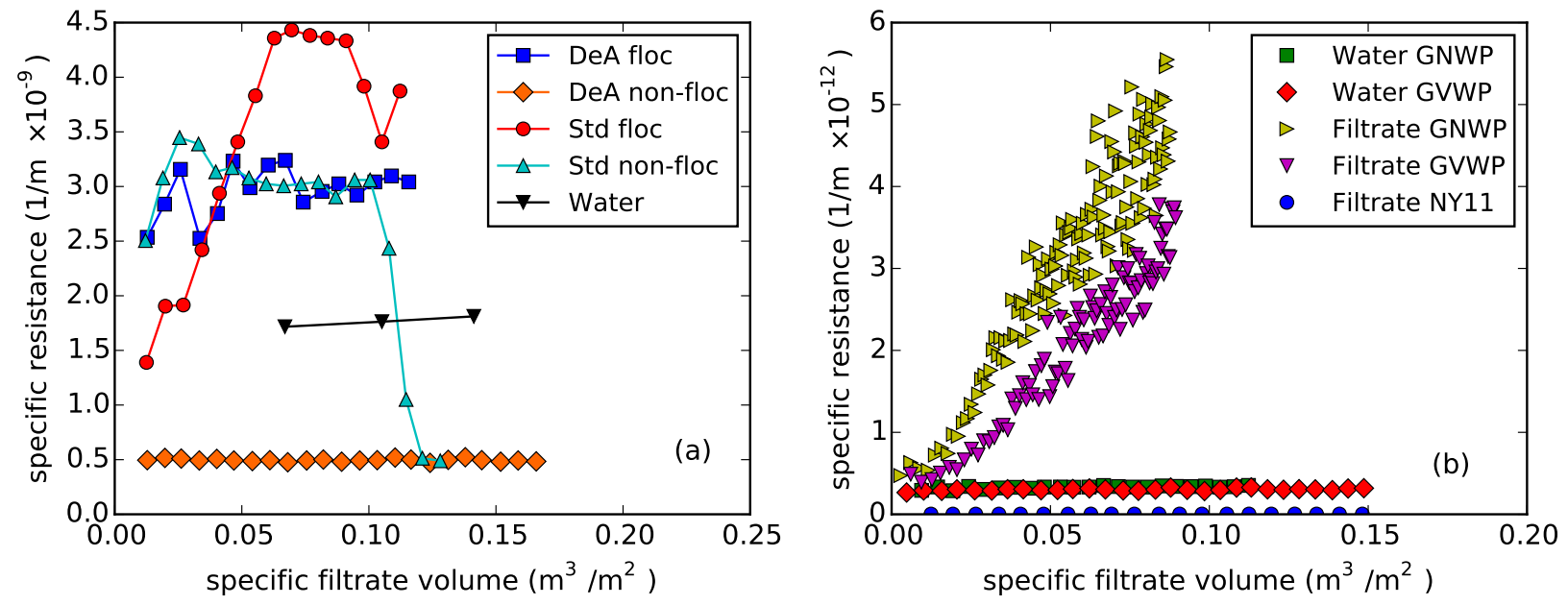

Figure 5: The results of polishing filtration on all bulk filtrates using filters with nominal pore size of $11 \mu \mathrm{m}$ (a), and results from two types of sterile filters $(0.22 \mu \mathrm{m}$ Millipore type GNWP, and $0.20 \mu \mathrm{m}$ Millipore type GVWP) used on the de-acetylated case (b) with water presented as controls in both. DeA = de-acetylated case, Std $=$ standard case. Increasing resistance over volume indicates plugging. 


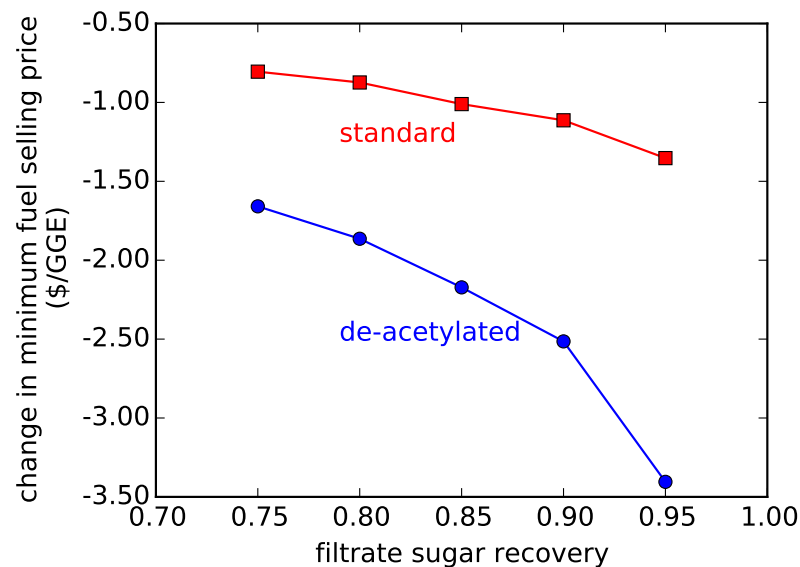

Figure 6: Techno-economic analysis of an enzymatic hydrolyzate solid-liquid separator, demonstrating change in minimum fuel selling price at $10 \%$ internal rate of return (change in production cost) when filter feed stream has been flocculated versus no treatment. 


\section{List of Tables}

1 Composition of feedstock and hydrolyzate slurry insoluble solids, expressed as mass percentage of major components . . 30

2 Primary sugar concentrations of liquors produced for each hydrolyzate . . . . . . . . . . . . . . . . 31 
Table 1: Composition of feedstock and hydrolyzate slurry insoluble solids, expressed as mass percentage of major components

\begin{tabular}{lcccccc}
\hline & Glucan & Xylan & Acetate & Lignin & Protein & Ash \\
\hline Virgin Feedstock & 36.1 & 22.3 & 1.7 & 17.1 & NA & 4.8 \\
Standard Hydrolyzate & 13.2 & 1.2 & 0.4 & 65.3 & 6.5 & 8.6 \\
De-acetylated Hydrolyzate & 43.2 & 5.6 & 0.1 & 41.9 & 4.1 & 3.7 \\
\hline
\end{tabular}


Table 2: Primary sugar concentrations of liquors produced for each hydrolyzate

\begin{tabular}{lcccc}
\hline & \multicolumn{2}{c}{ Monomeric (g/L) } & \multicolumn{2}{c}{ Total $(\mathrm{g} / \mathrm{L})$} \\
& Glucose & Xylose & Glucose & Xylose \\
\hline Standard Hydrolyzate & 80.2 & 49.3 & 88.2 & 55.5 \\
De-acetylated Hydrolyzate & 84.7 & 36.2 & 91.9 & 41.9 \\
\hline
\end{tabular}

